\title{
Intravenous iloprost for treatment failure of aerosolised iloprost in pulmonary arterial hypertension
}

\author{
M.M. Hoeper, E. Spiekerkoetter, V. Westerkamp, R. Gatzke, H. Fabel
}

\begin{abstract}
Intravenous iloprost for treatment failure of aerosolised iloprost in pulmonary arterial hypertension. M.M. Hoeper, E. Spiekerkoetter, V. Westerkamp, R. Gatzke, H. Fabel. C) ERS Journals Ltd 2002.

ABSTRACT: Treatment with aerosolised iloprost, a prostacyclin analogue, has beneficial effects in patients with pulmonary arterial hypertension (PAH). It is unclear if patients, whose clinical condition deteriorates under treatment with aerosolised iloprost, benefit from switching to continuous intravenous iloprost.

The current authors report on 16 patients with severe PAH who received continuous intravenous iloprost after primary or secondary failure of treatment with aerosolised iloprost. Determinants of efficacy were survival, New York Heart Association (NYHA) class, and walking distance in the 6-min walk test.

Of 93 patients with PAH treated with aerosolised iloprost, 16 required switching to intravenous iloprost for clinical deterioration. These patients had severe right heart failure with a cardiac index of $1.6 \pm 0.2 \mathrm{~L} \cdot \mathrm{min}^{-1} \cdot \mathrm{m}^{-2}$ and a mixed-venous oxygen saturation of $52 \pm 6 \%$. Five of these patients showed no improvement and eventually died. Three patients had further deterioration in NYHA class and exercise capacity; two of them underwent lung transplantation; the third patient is still alive. Eight patients showed marked clinical improvement; one underwent lung transplantation and the others are currently alive and stable. In the latter group of patients, the walking distance in the 6-min walk test increased from $205 \pm 94$ to $329 \pm 59 \mathrm{~m}$. It was not possible to identify clinical or haemodynamic factors that would predict whether switching from inhaled to intravenous iloprost would have a beneficial effect.

In patients with pulmonary arterial hypertension who deteriorated while being treated with aerosolised iloprost, switching to continuous intravenous iloprost caused substantial improvement in exercise capacity in eight of 16 patients but could not prevent progression of pulmonary hypertension in the remaining eight patients. Since it was impossible to predict the individual effects of this approach, intravenous prostaglandin treatment should be considered in pulmonary arterial hypertension patients who deteriorate while receiving iloprost aerosol.
\end{abstract}

Eur Respir J 2002; 20: 339-343.

Hannover Medical School, Hannover, Germany.

Correspondence: M.M. Hoeper

Department of Respiratory Medicine

Hannover Medical School

Hannover

Germany

Fax: 495115328536

E-mail: hoeper.marius@

mh-hannover.de

Keywords: Hypertension, pulmonary iloprost

prostacyclin

Received: December 52001

Accepted after revision: March 42002
Pulmonary arterial hypertension (PAH) is characterised by progressive obliteration of the pulmonary vascular bed that almost inevitably results in progressive right heart failure and death $[1,2]$. Treatment with continuous intravenous prostacyclin (epoprostenol) has been shown to improve exercise capacity, haemodynamics and survival in patients with pulmonary hypertension [3-5]. Alternatively, continuous intravenous infusion of iloprost, a stable prostacyclin analogue, is used in some countries and seems to be as efficient as intravenous epoprostenol in these patients $[6,7]$.

A major drawback of continuous intravenous prostaglandin treatment is the requirement of a permanent central venous access that is prone to infectious complications [3, 4]. To circumvent this problem, novel prostaglandins such as inhaled iloprost [8], oral beraprost [9], and subcutaneous treprostinil [10] have recently been introduced as alternatives. Furthermore, the orally available dual endothelin receptor antagonist bosentan is the first nonprostanoid substance for which efficacy has been demonstrated in randomised, controlled trials [11, 12]. It is tempting to use these new substances as noninvasive first line treatment of patients with $\mathrm{PAH}$ and to reserve intravenous prostaglandins for the most severe cases and treatment failures. However, it is unknown if intravenous prostaglandins do provide clinical benefit when the novel, noninvasive prostaglandins are not sufficiently effective.

Aerosolised iloprost is among the novel therapies that have recently been introduced for PAH [8]. In open studies, aerosolised iloprost had beneficial acute and long-term effects in this group of patients [13-16]. The efficacy of inhaled iloprost in patients with PAH was recently confirmed by a European randomised, placebo-controlled, multicentre trial that demonstrated significant improvement in exercise capacity and haemodynamics in patients treated with aerosolised iloprost (unpublished data). The inhaled route 
of administering iloprost has less side-effects than the intravenous approach and obviates the need of a permanent central venous access. However, concern has been raised that this form of treatment may be less effective than treatment with intravenous prostacyclin [17]. No study has yet addressed efficacy and safety of inhaled iloprost compared with intravenous epoprostenol or iloprost, respectively.

At Hannover Medical School, Germany, most of the patients with $\mathrm{PAH}$ have been receiving first line treatment with aerosolised iloprost since 1997. These patients have been followed closely, including repeated outpatient visits every 3 months and yearly follow-up right heart catheter examinations. If there was no improvement with aerosolised iloprost (primary treatment failure) or if a patient deteriorated after initial improvement (secondary treatment failure) switching to continuous intravenous iloprost was recommended, although it is unknown if patients whose clinical conditions deteriorate under treatment with aerosolised iloprost benefit from intravenous iloprost.

In this paper, the clinical results of $16 \mathrm{PAH}$ patients who received continuous intravenous iloprost after primary or secondary treatment failure with inhaled iloprost are described.

\section{Patients and methods}

Of 140 PAH patients referred to the authors' centre between February 1997 and August 2001, 93 received aerosolised iloprost as first line treatment (some patients with severe haemodynamic impairment were immediately treated with intravenous iloprost, while some received calcium channel blockers, oral beraprost sodium or subcutaneous treprostinil as first line treatments).

Treatment with aerosolised iloprost was continued for as long as the patients showed clinical improvement or stabilisation in New York Heart Association (NYHA) class II or III. Right heart catheterisations were performed before initiation of inhaled iloprost and 3 months later, followed by annual catheter studies or when indicated by clinical requirements. In case of progression of pulmonary hypertension, as determined by clinical assessment, 6-min walking distance and haemodynamic deterioration during repeated right heart catheterisations, the dose of inhaled iloprost was increased as described below. If there was further deterioration, treatment with continuous intravenous iloprost was initiated. Inhaled iloprost was tapered and discontinued within 3-7 days after intravenous therapy was started. Of the 93 patients treated initially with aerosolised iloprost, 16 were eventually switched to intravenous iloprost because of clinical and haemodynamic deterioration. Eligible patients were admitted on the waiting list for lung transplantation when intravenous treatment was begun.

Before treatment with aerosolised iloprost was started, all patients were informed about the investigational character of this therapy and the possibility that intravenous iloprost might be more effective. The authors' institutional review board approved this approach.

\section{Treatment with aerosolised iloprost}

Iloprost aerosol was generated by a jet nebuliser (IloNebß), Nebutec, Elsenfeld, Germany). All patients initially received a daily dose of $100 \mu \mathrm{g}$ divided into six daily inhalations as described elsewhere $[13,14]$. In patients with an unsatisfying response, the daily dose was increased up to $200 \mu \mathrm{g}$ divided into 8-9 daily inhalations.

\section{Treatment with intravenous iloprost}

Venous access was obtained by the insertion of a permanent catheter into a subclavian vein. Iloprost was administered using the CADD-1 pump (SIMS Deltec Graseby, Kirchseeon, Germany). Iloprost was started at a dose of $0.5 \mathrm{ng} \cdot \mathrm{kg}^{-1} \cdot \mathrm{min}^{-1}$ and was increased stepwise until side-effects precluded further dose escalation. After discharge from hospital, the patients were seen every 6-12 weeks in the outpatient clinic. If the clinical effects were judged as sufficient by the patient and their physician, the dose of iloprost was kept stable. In case of lack of improvement or deterioration, the dose was gradually increased until the emergence of intolerable side-effects. Follow-up visits consisted of history assessment, physical examination and 6-min walk testing. The functional NYHA class was determined according to recent recommendations for patients with pulmonary arterial hypertension [18]. All data presented in this manuscript were from the latest visit unless indicated otherwise. Right heart catheterisations were performed before changing therapy from aerosolised to intravenous iloprost but not routinely afterwards.

\section{Statistical analysis}

Data are presented as mean \pm SD unless indicated otherwise. Comparative statistics were not performed because of the small number of patients and the observational aspect of this investigation.

\section{Results}

Sixteen patients received intravenous iloprost for failure of treatment with inhaled iloprost. The patients' clinical characteristics, haemodynamic variables before initiation of intravenous iloprost, and exercise capacities are shown in table 1 . Two patients had porto-pulmonary hypertension (No. 6 and 11), while the others suffered from primary pulmonary hypertension. All patients had severe limitation of exercise capacity; three were in NYHA class III, and 13 in NYHA class IV. The walking distance in the 6-min walk test was $179 \pm 118 \mathrm{~m}$ (range $0-350 \mathrm{~m}$ ). Cardiac function was severely compromised as indicated by a cardiac index of $1.6 \pm 0.2 \mathrm{~L} \cdot \mathrm{min}^{-1} \cdot \mathrm{m}^{-2}($ range 


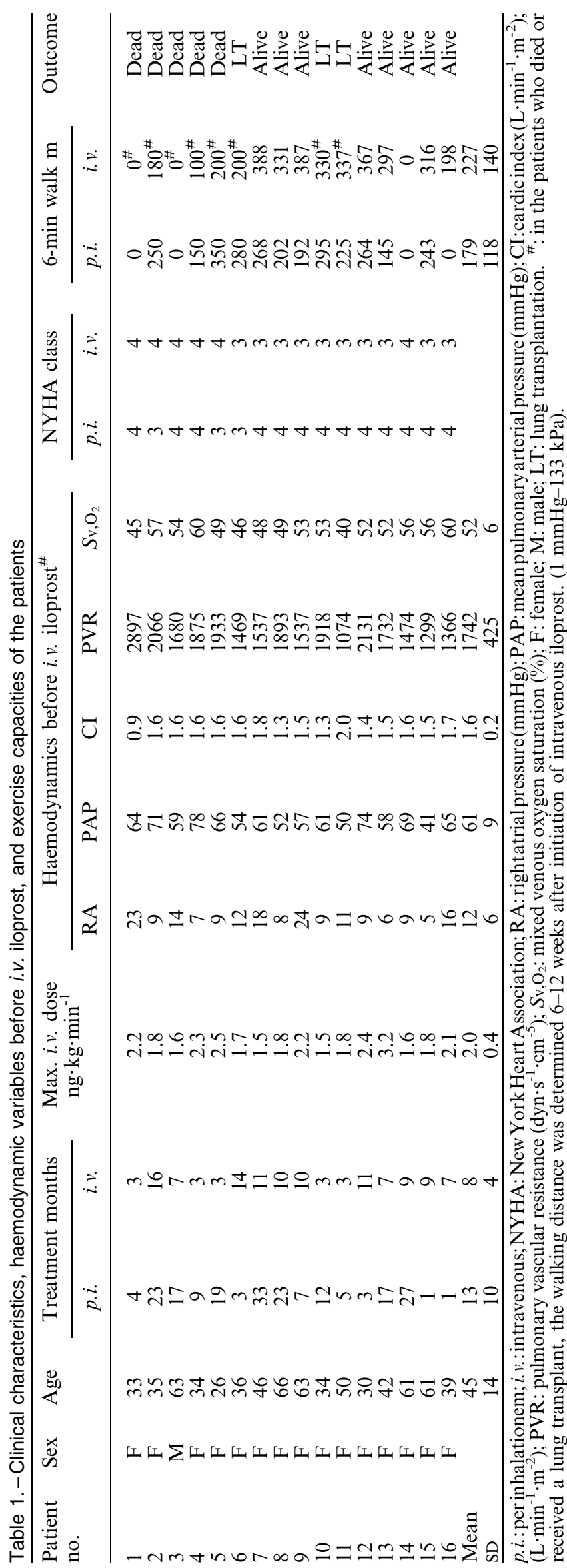

0.9-2.0 L $\cdot \min ^{-1} \cdot \mathrm{m}^{-2}$ ) and a mixed venous oxygen saturation of $52 \pm 6 \%$ (range $40-60 \%$ ). The patients had been treated with aerosolised iloprost for $13 \pm$ 10 months (range 1-33 months). Of the 16 patients who were switched to intravenous iloprost, six were treated for $<6$ months with inhaled iloprost. These patients had no substantial improvement with inhaled iloprost at any time. In contrast, the other 10 patients showed improvement in 6-min walking distance and haemodynamics for up to 24 months with inhaled iloprost but eventually haemodynamic and clinical deterioration occurred.

Of the 16 patients who received intravenous iloprost for failure of treatment with inhaled iloprost, eight did not show improvement of exercise capacity or NYHA class. Five of these patients died after 3-16 (median 3) months of intravenous treatment. Two patients underwent lung transplantation while one patient is alive, receiving intravenous iloprost for 9 months and awaiting lung transplantation. This patient is confined to a wheelchair due to advanced right heart failure. In contrast, the remaining eight patients showed substantial clinical improvement. One of these patients received a lung transplant 3 months after intravenous iloprost was started while the remaining patients were in stable clinical condition after receiving intravenous iloprost for $9 \pm 2$ months (range 7-11 months).

Before switching from inhaled to intravenous iloprost, three patients were in functional NYHA class III and 13 patients in NYHA class IV. After a mean treatment period of $9 \pm 2$ months, all patients who responded to treatment were in NYHA class III (table 1). In this subgroup of patients, the walking distance in the 6-min walk test increased from $205 \pm 94 \mathrm{~m}$ to $329 \pm 59 \mathrm{~m}$.

There were no significant differences between the patients who derived benefit from intravenous iloprost and those who did not in terms of age, duration of disease, duration of treatment with inhaled iloprost, haemodynamic variables, or vasoreactivity as determined by the acute haemodynamic response to inhaled iloprost (data not shown).

\section{Discussion}

There is substantial evidence from open studies that aerosolised iloprost is an effective treatment for $\mathrm{PAH}$ $[14,15]$. A recently concluded European placebocontrolled multicentre trial confirmed these observations (unpublished data). Because of these results it is expected that European regulatory agencies will grant approval for inhaled iloprost as treatment of PAH in the year 2002 .

A major drawback of this therapy is the relatively short duration of action of aerosolised iloprost. The haemodynamic effects are detectable only for 30-60 min after each inhalation [13] so that even with 6-9 inhalations $\cdot$ day $^{-1}$, continuous pulmonary vasodilation is not achievable. Although vasodilation is probably not the only mechanism by which prostaglandins act in $\mathrm{PAH}$, the short-lived haemodynamic action raised concerns that aerosolised iloprost 
might be less effective than continuous intravenous prostaglandins.

Prospective studies comparing inhaled iloprost with intravenous epoprostenol or iloprost, respectively, are not available. One way to find out whether intravenous prostaglandins are more effective than inhaled iloprost is to introduce intravenous treatment in those patients who deteriorate while receiving inhaled iloprost. In the current investigation, replacing inhaled iloprost by intravenous iloprost caused substantial increases in exercise capacity in eight of 16 patients whereas the remaining patients had no benefit. Seven of the patients in the latter group died or underwent lung transplantation, while seven patients in the former group were alive and substantially improved after $9 \pm 2$ months of intravenous treatment (one patient who underwent lung transplantation died in the early postoperative period). Two aspects of these findings are remarkable: first, intravenous iloprost was clearly more effective than aerosolised iloprost in some patients with PAH; second, half of the patients had no benefit from switching to intravenous iloprost. The superior efficacy of intravenous iloprost was anticipated but the finding that intravenous treatment failed to provide clinical improvement in half of the patients was surprising and disturbing at the same time. Several reasons may have accounted for the overall unsatisfying efficacy of intravenous iloprost in this highly selected subgroup of patients.

When initiated as first-line treatment, intravenous epoprostenol and iloprost have been reported to be effective in the vast majority of patients with $\mathrm{PAH}$ $[3,4,19]$. In the current authors' centre, intravenous treatment was given only to patients with no longterm response to aerosolised iloprost. Thus, it is possible that a subgroup of patients were selected who were unresponsive to treatment with prostaglandins. The authors were unable to identify clinical or haemodynamic variables that would discriminate these patients from those who remain responsive to intravenous iloprost despite failure of inhaled iloprost.

Treatment with inhaled iloprost was performed for $13 \pm 10$ months before the patients received intravenous iloprost. Thus, the patients had more advanced disease than they would have had if intravenous iloprost was instituted as first-line treatment. The fact that the patients in this study had a cardiac index of $1.6 \pm 0.2 \mathrm{~L} \cdot \mathrm{min}^{-1} \cdot \mathrm{m}^{-2}$ and a mixed venous oxygen saturation of $52 \pm 6 \%$ at the time when intravenous treatment was introduced, underscores the notion that this group of patients had very severe disease. This fact probably contributed to the high rate of nonresponders to intravenous iloprost. However, the possibility that some of the patients would have fared better with earlier introduction of intravenous treatment cannot be ruled out and it will be a major task of further studies to determine criteria that help to decide when a patient should be switched from noninvasive to invasive prostaglandin treatment.

The optimal dosing regimen of intravenous prostaglandins in patients with PAH is unclear. Continuous administration of prostacyclin or iloprost may cause tachyphylaxis. Therefore, it is common practice in most centres to gradually increase the dose over time $[4,20]$ although it is still uncertain to what extent this is really necessary. In several centres, the dose of intravenous epoprostenol or iloprost is increased whenever side-effects wane. At least some patients might be overtreated with this approach [21]. A slightly more conservative protocol was used in this study by increasing the dose of intravenous iloprost only when the clinical efficacy was unsatisfactory. With this regimen, the mean dose of iloprost in the patients was $2.0 \pm 0.4 \mathrm{ng} \cdot \mathrm{kg}^{-1} \cdot \mathrm{min}^{-1}$, which is close to the mean dose of $2.1 \mathrm{ng} \cdot \mathrm{kg}^{-1} \cdot \mathrm{min}^{-1}$ that has been used by Higenbottam et al. [6] in another study. It is possible that a more aggressive dosing regimen might have been more efficient. However, the doses of intravenous iloprost were not different in patients who gained benefit and those who did not.

The fact that intravenous iloprost was used instead of intravenous epoprostenol may also be a matter of debate. The evidence for efficacy of epoprostenol in PAH is much stronger than for intravenous iloprost and only a few studies have been performed to compare both substances [6, 7]. From these data, it seems likely that iloprost is as effective as epoprostenol in the treatment of pulmonary hypertension but this has not been scientifically proven. Iloprost has the advantage of being much more stable than epoprostenol [22] and is therefore easier to handle. In addition, the longer half-life makes iloprost potentially safer than epoprostenol, since interruption of drug supply does not result in immediate cessation of the drug's action. Furthermore, in Germany, iloprost is less expensive than epoprostenol. Nevertheless, the authors cannot exclude with certainty that these results might have been better if epoprostenol had been used.

This study has several limitations including the small number of patients. The criteria for switching from aerosol to intravenous treatment were not rigorously defined. The most important limitation comes from the retrospective analysis and the fact that there was no control group. It has to be kept in mind that the presented data were merely observational rather than from a clinical trial. In light of the strong evidence for the efficacy and potentially life-saving effects of intravenous prostaglandins in $\mathrm{PAH}$, it would have been unethical to withhold these substances from severely ill patients who deteriorate while receiving inhaled iloprost.

This study is further limited by the lack of follow-up data from right heart catheterisation. However, since dosing of iloprost was adjusted according to clinical patterns in the majority of patients, no indication for repeated cardiac catheterizations was seen.

Despite these limitations, this data clearly demonstrates that continuous intravenous iloprost may have substantial favourable effects in patients with pulmonary arterial hypertension who deteriorate while being treated with aerosolised iloprost. However, not all patients derive benefit from this approach. Since there seems to be no means to identify patients who will respond to intravenous iloprost after treatment failure with inhaled iloprost, intravenous prostaglandin treatment should be considered in all pulmonary 
arterial hypertension patients who deteriorate while receiving iloprost aerosol.

\section{References}

1. Gaine S. Pulmonary hypertension. JAMA 2000; 284: 3160-3168.

2. Rubin LJ. Primary pulmonary hypertension. $N$ Engl J Med 1997; 336: 111-117.

3. Barst RJ, Rubin LJ, Long WA, et al. A comparison of continuous intravenous epoprostenol (prostacyclin) with conventional therapy for primary pulmonary hypertension. The Primary Pulmonary Hypertension Study Group. N Engl J Med 1996; 334: 296-302.

4. McLaughlin VV, Genthner DE, Panella MM, Rich S. Reduction in pulmonary vascular resistance with longterm epoprostenol (prostacyclin) therapy in primary pulmonary hypertension. N Engl J Med 1998; 338: 273-277.

5. Badesch DB, Tapson VF, McGoon MD, et al. Continuous intravenous epoprostenol for pulmonary hypertension due to the scleroderma spectrum of disease. Ann Intern Med 2000; 132: 425-434.

6. Higenbottam TW, Butt AY, Dinh-Xaun AT, Takao M, Cremona G, Akamine S. Treatment of pulmonary hypertension with the continuous infusion of a prostacyclin analogue, iloprost. Heart 1998; 79: 175179.

7. Higenbottam T, Butt AY, McMahon A, Westerbeck $\mathrm{R}$, Sharples L. Long-term intravenous prostaglandin (epoprostenol or iloprost) for treatment of severe pulmonary hypertension. Heart 1998; 80: 151-155.

8. Olschewski H, Walmrath D, Schermuly R, Ghofrani A, Grimminger F, Seeger W. Aerosolized prostacyclin and iloprost in severe pulmonary hypertension. Ann Intern Med 1996; 124: 820-824.

9. Galiè N, Humbert M, Vachiery JL, et al. Effects of beraprost sodium, an oral prostacyclin analogue, in patients with pulmonary arterial hypertension: a randomized, double-blind, placebo-controlled trial. J Am Coll Cardiol 2002; 39: 1496-1502.

10. Simonneau G, Barst RJ, Galie N, et al. Continuous subcutaneous infusion of treprostinil, a prostacyclin analogue, in patients with pulmonary arterial hypertension: a double-blind randomized controlled trial. Am J Respir Crit Care Med 2002; 165: 800-804.

11. Channick RN, Simonneau G, Sitbon O, et al. Effects of the dual endothelin-receptor antagonist bosentan in patients with pulmonary hypertension: a randomised placebo-controlled study. Lancet 2001; 358: 11191123.

12. Rubin LJ, Badesch DB, Barst RJ, et al. Bosentan in patients with pulmonary artery hypertension: a randomized, placebo controlled, multicenter study. $N$ Engl J Med 2002; 346: 896-903.

13. Hoeper MM, Olschewski H, Ghofrani HA, et al. A comparison of the acute hemodynamic effects of inhaled nitric oxide and aerosolized iloprost in primary pulmonary hypertension. J Am Coll Cardiol 2000; 35: 176-182.

14. Hoeper MM, Schwarze M, Ehlerding S, et al. Longterm treatment of primary pulmonary hypertension with aerosolized iloprost, a prostacyclin analogue. $N$ Engl J Med 2000; 342: 1866-1870.

15. Olschewski H, Ghofrani HA, Schmehl T, et al. Inhaled iloprost to treat severe pulmonary hypertension. An uncontrolled trial. Ann Intern Med 2000; 132: 435-443.

16. Wensel R, Opitz CF, Ewert R, Bruch L, Kleber FX. Effects of iloprost inhalation on exercise capacity and ventilatory efficiency in patients with primary pulmonary hypertension. Circulation 2000; 101: 2388-2392.

17. Machherndl S, Kneussl M, Baumgartner $\mathrm{H}$, et al. Long-term treatment of pulmonary hypertension with aerosolized iloprost. Eur Respir J 2001; 17: 8-13.

18. Rich S. Executive summary from the world symposium on primary pulmonary hypertension 1998. http:// www.who.int/ncd/cvd/pph.html. Date last updated: November 21 2001. Date last accessed: February 20 2002.

19. Shapiro SM, Oudiz RJ, Cao T, et al. Primary pulmonary hypertension: improved long-term effects and survival with continuous intravenous epoprostenol infusion. J Am Coll Cardiol 1997; 30: 343-349.

20. Barst RJ, Rubin LJ, McGoon MD, Caldwell EJ, Long WA, Levy PS. Survival in primary pulmonary hypertension with long-term continuous intravenous prostacyclin. Ann Intern Med 1994; 121: 409-415.

21. Rich S, McLaughlin VV. The effects of chronic prostacyclin therapy on cardiac output and symptoms in primary pulmonary hypertension. $\mathrm{J} \mathrm{Am} \mathrm{Coll}$ Cardiol 1999; 34: 1995-1996.

22. Grant SM, Goa KL. Iloprost. A review of its pharmacodynamic and pharmacokinetic properties, and therapeutic potential in peripheral vascular disease, myocardial ischemia and extracorporeal circulation procedures. Drugs 1992; 43: 889-924. 